\title{
LXXIV. An attempt to determine the definite and simple proportions, in which the constituent parts of unorganic substances are united with each other
}

Jacob Berzelius M.R.A.

To cite this article: Jacob Berzelius M.R.A. (1813) LXXIV. An attempt to determine the definite and simple proportions, in which the constituent parts of unorganic substances are united with each other, Philosophical Magazine Series 1, 42:188, 440-463, DOI: 10.1080/14786441308638364

To link to this article: http://dx.doi.org/10.1080/14786441308638364

曲 Published online: 27 Jul 2009.

Submit your article to this journal ¿

ЏII Article views: 3

Q View related articles $\square$ 


\section{[ 440$]$}

LXXIV. An Attempt to determine the definite and simple Proportions, in which the constituent Parts of unorganic Substances are united with each other. By JACOB BERzELivs, Professor of Medicine and Pharmacy, and M.R.A. Stockholm.

[Continued from p. 386.]

\section{SECOND CONTINUATION.}

[From the original Germen, as arranged, with some little Modification of the Author's Subdivisions, by Professor Grbant.]

\section{Nitric Acid and Nitrates, as affording Proofs} THAT NiTROGEN IS NOT CHEMICALLY SIMPLE.

I

Trust that in my Essay on definite Proportions, and in it First Continuation, I have completely established the doctrine, that all salts are composed of an acid and a hase in such proportions, that the oxygen contained in the acid is a multiple by a whole number of the quantity contained in the base. - But in these investigations I have not yet treated of the nitric acid. I intended not to have made known my analysis of the nirates before $I$ published my investigations relating to animal substances; but they may more properly be introduced on the present occasion, partiy because they confirm the proposition which has been mentioned, and partly because they may serve as an addition to the proofs of the compound nalure of nitrogen which have been stated in the First Continuation of my Essay.

\section{Nitric Acid.}

Attempt to determine its Composition from its Capacity of Saturation.

In this investigation a great difficuly arises from the inpossibility of depriving the nitrates of their water of crystal. Jization, without decomposing more or less of the acid; so that one cannot infer with ertainty the quantity of the acid, from that of the base which is leit behind; a circunstance which long deterred me from the undertaking. But since it became necessary for the inferences which nere to be drawn from my analyses of animal bodies, to determine how far vitrogen, from the modification of its electrical properties, might be considerd as a simple body, I determined to artempt to overcome thene diffoulties, and I have succed ded far beyond my expectation. The nitrates, which I chuse for this investigation, were those of baryta, protoxide of lead, and ammonia. 


\section{Nitrate of Baryta.}

In order to obtain this salt in perfect purity, I heated it to ignition in a silver crucible, dissolved it in water. filtered the solution, saturated it with pure nitric acid, and evaporated it until it crystallized. In order to determine the quantity of water of crystallization, which I supposed to exist in the salt, 1 introduced 10 grammes into a small retort, which instead of a receiver was furnished with a tube filled with muriate of lime. The nitrate of baryta decrepitated in the heat, and fell into a fine powder: J continued the heat until the salt was fused, and began to emit oxygen, The retort had nuw lost 052 gr. and the tube had acquired -046. I have shown that the water, which a salt loses by decrepitation, can he no water of crystallization, but can only be inclosed mechanically in the crystals; so that it can easily be removed by powdering the salt and by drying it in a warm place. It is also to be supposed, for the reasons which have been given, that crystals, which decrepitate in the fire, contain no water chemically combined with them. I therefore consider the result of this experiment on the nitrate of baryta as a proof, that it contains no water of crystallization.

Ten grammes of finely powdered and very well dried nitrate of baryta were dissolved in water in a platina crucible, sulphuric acid was added, and the mixture was dried and ignited. The sulphate of baryta, thus obtained, weighed $8.867 \mathrm{gr}$. and, according to the analysis already related, contained $5.825 \mathrm{gr}$. of baryia. Consequently 100 parts of nitric acid had saturated $\mathbf{1 4 0}$ of baryta, in which there are 14.64 parts of oxygen.

Ten more grammes of nitrate of baryta-were dissolved in water, and sulphate of ammonia was added to the solution, whence were obtained $8.907 \mathrm{gr}$. of sulphate of baryta, containing .5 .846 of baryta; so that 100 parts of nitric acid should saturate 140.73 of baryta, containing 14.13 of oxygen.

\section{Nitrate of the Protoxide of Lead.}

The same appearances, as have been described with respect to the preceding salt, justify us in concluding with respect to this also, that it contains no water of crystallization.

Twenty grammes of finely powdered and very well dried nitrate of the protoxide of lead were ignited in a platina crucible, and afforded $13.445 \mathrm{gr}$. of protoxide. Consequently 100 parts of this salt contain $67 \cdot 2225$ of the protoxide 
oxide and 32.7775 of nitric acid; or 100 parts of nitric acid saturate 205.1 of protoxide of lead, containing 14.66 of oxygen: [since this protoxide contains $7 \cdot 15$ per cent. of oxygen. Gil.s.]

These two experiments seem to show, that 100 parts of nitric acid saturate as much of a base as contains $14 \frac{2}{3}$ parts of oxygen. But if this acid is composed of 30.5 parts of nitrogen and $69 \cdot 5$ of oxygen, as Gay-Lussac'reports in his Essay on the combinations of the gaseous bodies, this quantity of oxygen, $69^{\circ} 5$, is not a multiple by any whole number of $14 \cdot 66$, but falls between four and five times that quantity. If, on the other hand, we consider the nitric acid as composed of 100 parts of ammonium and 662 parts of oxygen, as I have done, or of 13.12 of ammonium and 86.88 of oxygen per cent. we have at once $14.66 \times 6=87 \cdot 9$, and the nitric acid contains six times as much oxygen as the base with which it is saturated. The slight difference of 1 per cent. between the determinations from the composition of the base and from the weight of the gases, occurs also, as we have seen, in the case of the carbonic acid, and depends therefore not on an error in principle, but on a small inaccuracy in the numbers on which the calculation is founded.

Perhaps it will be objected to me, that although the salts here analysed afforded no water of crystallization in their decrepitation, they may have retained it so firmly as not to have parted with it except together with the acid; and if we allowed that they contained exactly so much water of crystallization, as to have its oxygen equal to that of the base, faccording to the law which will be more fully explained in the Third Continuation, G.] the remaining nitric acid, if considered as composed of nitrogen and oxygen, would contain not quite four times as much oxygen, and if as of anmonium and oxygen, exactly five times as much as the base. This objection I shall put to the test in the case of the following salt.

\section{Nitrate of Ammonia.}

According to the view which has been mentioned, this salt must be so composed that 100 parts of ammonia saturate 267 of nitric acid [since for 100 parts of ammonium ammonia must contain 88 and the nitric acid 662 parts of oxygen, G.]. But if we reckon according to the volumes of the gaseous component parts, as they are assigned by Gay-Lussac, the nitric acid contains for 100 cubic inches of nitrogen 200 of oxygen, and ammonia for the same measure of nitrogen 
300 of hydrogen gas. In this case it is evident that the acid can only contain an integral multiple of the oxygen of the nitrogen, and not of the whole quantity contained in the ammonia. And if such were the true composition of these substances, this would prove nothing for or against the composition of nitrogen; but it would demonstrate that hydrogen contains no oxygen.

If this statement were true, the nitrate of ammonia when slowly decomposed by heat, would afford equal parts of nitrogen and nitrous oxide; for 100 cubic inches of hydrogen gas take up 150 of oxygen, and the remaining 50 of oxygen form with 100 of nitrogen 100 of nitrous oxide, and consequently 100 parts of nitrogen should be disengaged. But we know that the quantity of nitrogen in the nitrous oxide obtained from the nitrate of ammonia is not considerable, although it is never wholly wanting. Consequently this view of the composition of nitrate of ammonia cannot possibly be correct.

Since the nitrate of baryta, which is decomposed by mixture with the sulphate of ammonia, does not alter its state of neutralisation, it is obvions that ammonia follows the same law of saturation with the nitric acid relatively to the fixed bases of salts as with the other acids. Hence it is clear, that since 100 parts of nitric acid are neutralised by a quantity of baryta or protoxide of lead which contain $14 \cdot 66$ parts of oxygen, they must also saturate as much ammonia as contains the same quantity of oxigen. The nitrate of ammonia must therefore be thus constituted;

$$
\begin{array}{cccc}
\text { Nitric acid ... } & 76.18 & 100.000 & 320 \\
\text { Ammonia ... } & 23.82 & 31.266 & 100
\end{array}
$$

But since the nitrate of ammonia cannot be obtained without water of crystallization, this determination camot be directly confirmed. It may however be supposed, that, like the muriate of ammonia, it contains a quantity of water of which the oxygen is equal to that of the base, and that consequently in the nitrate of ammonia one third part as much water of crystallization is contained as it is capable of producing when decomposed by oxidation. According to this, 100 parts of nitric acid, with 31.266 parts of ammonia, and 16.61 of water, must represent the crystallized salt; and 100 parts of crystallized nitrate of ammonia must consist of

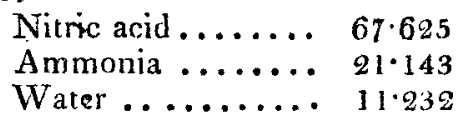

In order to examine this more particularly, I mixed in a 
small glass retort 5 grammes of crystallized and dry nitrate of ammonia with $10 \mathrm{gr}$. of finely powdered clean and newly burnt lime. I fitted to the retort a small tubulated receiver, in which was a little unslaked lime, and from the tube of which a small tube of glass, filled with muriate of lime, allowed the ammoniacal gas to escape. The retort was heated for twelve hours on a sand-bath, in a temperature which was not sufficient for the decomposition of the newly formed nitrate of linte; and now the retort had lost $1 \cdot 1$ gr. while the receiver and the alkali har acquircd o.059. Both still smelt a little of ammonia; a proof that they retained a small quantity of this substance together with the water. Consequently in this experiment 100 parts of nitrate of ammonia had afforded 20.82 of ammonia, which differs only by $\frac{32}{1000}$ from the quantity determined by calculation; a variation which depends partly on the unavoidable imperfections of the experiments, and partly perhaps on small errors in the numbers on which the calculation is founded. When I wished to expel the water from the nitrate of lime, and for this purpose had fitted to the retort a glass tube filled with muriate of lime, the acid was immediately decomposed, and the experiment afforded no result that could be of any. use.

If, as these experiments seem to agree in proving, the composition of the nitrate of ammonia here determined is the true one, it cannot be completely "converted into water and nitrous oxide; but a portion of nitrogen must always be disengaged, which amounts to $\frac{1}{5}$ of that of the acid, or $\frac{1}{4}$ of that of ilse alkali. But commonly more nitrogen is formed, since the temperature is too much raised, and some uncombined acid is disengaged, which partly distils nver with the water, and partly collects in the retort with the salt. The higher the temperature, the more acid is disengaged, and the more nitrogen appears; so that, when a complete detonation takes place, no nítrous oxide is formed.

In an cxperiment, in which I slowly decomposed 5 grammes of nitrate of ammonia in a small retort over a spirit lamp, collected the water in a receiver, and brought the gas through a glass tube filled with muriate of lime, the water obtaincd was slightly acid, and saltish. It weighed, together with that which the muriate of lime had taken up, $2.3 \mathrm{gr}$.; and after evaporation, it left behind $\cdot 295 \mathrm{gr}$. of nitrate of ammonia; so that the water amounted only to $2.005 \mathrm{gr}$. There remained in the retort $345 \mathrm{gr}$. of salt still undecomposcd, and deciledly acid. If we neglect the uncombined acid contained in the water and in the salt, it 
appears that only " $4.365^{\prime \prime}[4 \cdot 36] \mathrm{gr}$. of the salt were decomposed, which had afforded $2.005 \mathrm{gr}$. of water, and had emitted $2.36 \mathrm{gr}$. of gas. According to the principle stated above, $\frac{x}{4}$ of this water, or $\cdot 5$ gr. must have been water of crystallization. If we now compute how much water of crystallization the $4.365 \mathrm{gr}$. of nirrate of ammonia must contain, according to the preceding determination of 11.232 per cent., we find the quantity $4005 \mathrm{gr}$; and according to the same determination, the gas disengaged from $4 \cdot 365$ gr. of salt must amouut to $2.4 \mathrm{gr}$. If now we recollect, that both the undecomposed salt and the water obtained contained uncombined acid, we easily perceive that this little variation of $\frac{1}{30}$ of the weight of the salt depends on the excess of acid; for, while this excess increases the weight of the undecomposed salt, it must also diminish that of the products of the decomposition. I therefore consider this experiment as a new proof of the accuracy of the composition of the nitrates, as here determined.

\section{Conclusion.}

From these experiments we obtain the following general result :

1. In the nitrates, the acid contains six times as much oxygen as the lase; and since this proportion does not hold good when we consider the acid as composed of nitrogen and oxygen, we must consider the nitric acid as composed of ammonium and oxygen. But if nitrogen eaunot be considered as a simple element in the nitrates, in which ammonium occurs in the [negative] modification of electricity, it can scarcely be otberwise in any part of organic nature.

2. The nitrate of ammonia is so constituted, that the nitric acid contains twice as much oxygen, as is required, in order to saturate the hydrogen which may be obtained from ammonia. The crystallized salt contains a quantity of water of crystallization, of which the oxygen is equal to that of the alkali. The nitrogen of the acid is to that of the alkali in the proportion of 5 to 4 . But the ammonium in the alkali is to that in the acid as 6 to 5 . When the salt is decomposed by heat, half of the whole quantity of nitrogen is disengaged in the form of nitrogen. This is the general law of the composition of the nitrate of ammonia. But the numerical determinations cannot be considered as stristly accurate, until the composition of those bodies, of which the salt consists, or which may be formed from it, agrees with them to the last places of decimals; at present they can only be regarded as approximations, which 
are however so far of material value, as they lead us with some certainty to the traces of the laws of nature.

That the ammonium of the alkali is not here an integral multiple of that of the acid, depends on the same cause as the apparently anomalous progressions of several combustible bodies, of which I have partly spoken already, and shall partly have occasion to speak more particularly in treating of the vegetable acids.

The analysis of the nitrate of ammonia may be considered as a formal proof of the existence of oxygen in hydrogen: for there can be no other reason why the oxygen of the acid, when considered as formed from nitrogen, should not be a multiple of that of the base by a whole number. But this analysis seems at the same time to show, that I have estimated the quantity of oxygen, in the First Continuation of ny Essay, much too high, and perhaps at least four times as much as the truth.

Since I have reason to believe from my investigation of the composition of ammonia, and of the neutral nitrates, that nitrogen is to be considered as a higher degree of oxidation of the same radical that forms ammonia, I think it follows from the same grounds, although not with the same force of evidence, that hydrogen must consist of the same radical in a lower degree of oxidation. It appears however, that the oxygen of the hydrogen should on this supposition be a multiple of that of any body with which water can combine, by some whole number, which lies between those of the oxygen in water and in the other substance, exactly as we shall find that of the oxygen in nitrogen with respect to the neutral nitrates. But this cannot be, if water really contaius only $11 \frac{3}{4}$ per cent. of hydrogen. If on the other hand water really contained more than $11 \frac{3}{4}$ per cent. of hydrogen, as Mr. Gay-Lussac has concluded from some reasons with which $I$ am unacquainted, the last-mentioned number, with which most of the analyses of bodies containing water agree best, would belong to the metallic ammonium, and the difference between the quantity of hydrogen and ammonicim in water would depend on the oxygen of the hydrogen. If however, as is most probable, future analyses of water, performed with accuracy proportional to the present state of the investigations, should still make the quantity of hydrogen in water accurately or very nearly 11.75 per cent., it will be difficult to reconcile the existence of oxygen in hydrogen with the calculations relating to multiple proportions. Since however this, as we shall hereafter find, happens also in some cases with respect to the 
oxygen in nitrogen, it cannot be considered as a decisive argument against the existence of oxygen in hydrogen.

I must also observe, that it is not yet possible to determine with certainty which series of proportions is the more correct, that which is determined from the weight of the gases, or that which is deduced from the analyses of several saline bases which $I$ have performed. I must however confess, that I believe the quantity of oxygen which I have assigned to these bases is too great : for, if we lessen it, the whole of the results will agree better together, as their discordance is increased by making it greater. If, for example, we take ammonia as containing $46^{\circ} \cdot 6$ of oxygen, and water as composed of 11.7 .5 of bydrogen and 88.25 of oxygen, every thing agrees perfectly with these numbers.

\section{Subntrates and Subsubnitrates.}

[Transferred by GILBERT from the Third Continuation.]

\section{Sulnitrate of the Protoxide of Lead.}

I have obtained this salt by treating the neutral nitrate with a smaller quantity of caustic ammonia than is necessary for its complete decomposition. The white precipitate, which was obtained, being well edulcorated, was strongly dried and ignited in a small glass retort: it afforted nitrous acid and oxygen gas, without any traces of acid being condensed; so that it contains no water of crystallization. It left 80.5 per cent. of fine lemon-coloured protoxide of lead: so that the salt consists of

$$
\begin{array}{lll}
\text { Nitric acid } \ldots . . . & 19.5 & 100 \\
\text { Protoxide of lead } & 80.5 & 413
\end{array}
$$

But in 80.5 parts of the protoxide there are 5.72 of oxygen, and in $19 \cdot 5$. of nitric acid there are 17.096 of oxygen; and $5 \cdot 72 \times 3=17 \cdot 16$ : so that in this salt the acid contains three times as much oxygen as the base, and saturates twice as much of the base as in the neutral nitrate of the protoxide.

\section{Subsulnitrate of the Protoxide of Lead.}

Another quantity of nitrate of the protoxide of lead was mixed with so much ammonia, that not only all the protoxide was precipitated, but also the fluid, when it had been digested several hours on the precipitate, remained still alkaline. The precipitate was washed as long as the water continued to dissolve any part of it. The white salt of lead, dried in the sun, was then placed in a small retort upon a strongly heated sand bath, so that the water was still more thoroughly expelled; it then became yellow, but parted 
only with its water, without suffering a particle of the acid to escape. The salt, thus dried, left after ignition 90.3 per cent. of oxide; and in this process only nitrous vapours and oxygen were disengaged, without an atom of liquid acid. These 90.3 parts of protoxide of lead contained 6.457 of oxygen. And if we consider the nitric acid as consisting of ammonium and 87.88 per cent. of oxygen, the 9.7 parts contain $8.52 t$ of oxygen, which is much less than twice the oxygen of the base: but if we consider the nitric acid as consisting of 30.5 parts of nitrogen and 69.5 of oxygen, $9 \cdot 7$ parts of nitric acid contain 674 of oxygen; that is, neglecting the small difference of 317 , which may easily have arisen from an error of observation, a quantity of oxygen equal to that of the base.

This result appeared in be the mure striking, as it seemed to contradicl my earlier icieas respecting the composition of the nitric acid; for I had not here to do with a double subsalt of lead: I had indeed been long acquainted with such a subacetate, and I particularly sought for it in this case; having observed that if one buils the acetate of the protoxide of lead with more of the protoxide, one obtains a combination which does not crystallize, which acts on vegetable colours like an alkali, and dries with heat into a mass of a gummy appearance. If this combitation is digested with still more of the protoxide, the protoxide expands and becomes white, the solution loses more and more of the lead that it contains, and retains at last an astringent taste, without sweetness. The white precipitate thus formed dissolves in boiling water, and shoots from it into feathery crystals with a silky gloss. I have not yet gone so far as to be able to make out with certainty the composition of this salt ; but I have found that it contains much more metal than the salt with the appearance of an extract, and can be converted into it again by the addition of acetic acid. These two degrees of the subsalts may be termed subsalts and subsubsalts.

I by no means expected, from the general law of the composition of salts which I have developed, that it would be necessary here to consider the nitric acid as composed of nitrogen and oxygen. Either (A) the observation must have been incorrect, or $(B)$ the analysis of the neutral nitrate of the protoxide of lead must have been inaccurate, or (C) there must bave been some cause, with which I am unacquainted, that nitrogen is affected in the nitric acid, when it is saturated with the greatest possible quantity of a base, as a simple substance, not containing any oxygen, or (D) the 
(D) the last-mentioned salt may have been a double combination of a subnitrate of the protoxide of lead, differently modified, with a hydrated protoxide.

In order to investigate which was the most probable of all these possibilities, I repeated once more the examination of this salt. After drying it in a water bath, the water of crystallization was driven off in a small glass retort in a sand bath. I call it water of crystallization, because the salt changed its colour from white to yellow when it was expelled. It amounted in one experiment to 2.30 , and in another to 2.32 per cent. The ignited salt left 88.1 of protoxide, which was not diminished by fusion. Consequently the salt was thus constituted :

$$
\begin{array}{llc}
\text { Protoxide of lead } & 83 \cdot 10 \\
\text { Nitric acid } & \ldots & 9 \cdot 5[8] \\
\text { Water } & . & 2 \cdot 32
\end{array}
$$

The view (C) of the composition of this salt I should be least of all disposed to admit, and therefore took care to examine all the rest before this. The quantity of the protoxide here found contains 6.299 parts of oxygen; that of the acid either 6.66 or 8.4112 , accordingly as we consider nitrogen or ammonium as its radical; and the water contains 2.05. Since neither of the two numbers belonging to the acid on these different suppositions perfectly agrees with the quantity of oxygen contained in the base; I imagined that according to the hypothesis (D) the salt might be thus constituted : the nitric acid being combined with $\frac{2}{3}$ of the protoxide, and forming with it a subsalt, in which the acid contained twice as much oxygen as the base, the remainiug $\frac{1}{3}$ might be combined with water as a hydrate, in which the oxygen of the water and of the protoxide might be equal : and the whole might in some measure resemble a double salt, in which the oxygen was contained in the smallest quantity in the water, that of the protoxide being three times as much, and that of the nitric acid four. This view agrees with the result of the experiment; but that it probably is not the true one, I am persuaded from the consideration of the other sutmitrites, which rather seem to indicate, that we must consider the acid in these combinations as having nitrogen for its radical, since on this supposition it would contain an equal quantity of oxygen with the base, and the water $\frac{1}{3}$ as much.

That this view of the subject, according to which we are to consider the nitric acid as composed of nitrogen and oxygen, dues not agree with the neutral nitrate of the protoxide of lead, if this contains 205.1 parts of the protoxide Vol. 42. No. 188. Dec. 1813. F f 
to 100 of nitric acid, we have already seen in the examination of this salt. I therefore repeated once more the analysis of the neutral nitrate.

For this purpose I dried the finely powdered neutral nitrate of the protoxide of lead in the sunshine, and, after some hours, I exposed ten grammes of it in a small glass retort to a bigher temperature, until the protoxide, deprived of its acid, was half vitrified, and the retort began to melt. Neither in the neck of the retort, nor in the receivers, had a single drop of acid been condensed; a proof that this nitrate contains no water. The weight of the retort was now only increased 6.729 gr. by that of the residuum; and it lost nothing more by further exposure to heat, although it was now completely flattened by partial fusion.

I have repeated this experiment several times with the most careful attention, both in retorts and in a platina crucible, and it always afforded results which only varied from $67 \cdot 3$ to $67 \cdot 31$ of the protoxide of lead for 100 of the salt. This is somewhat more than the 67.222 , which I had found in my former experiments; [and hence the neutral nitrate contains 205.87 parts of the protoxide to 100 of nitric acid, G.] The neutral nitrate of the protoxide of lead, which was employed for these experiments, produced not the least turbidness with the nitrate of the protoxide of silver, and the remaining protoxide of lead emitted, when dissolved in nitric acid, no gas, as would have been to be expected from the analogy of the alkaline and earthy nitrates. which have been exposed to heat. No more gas was evolved from $6.73 \mathrm{gr}$. of half vitrified protoxide of Jead than occupied the bulk of a pea; I therefore consider this as atmospherical air, which had been mechanically absurbed by the oxide in cooling.

Hence it is most clearly established: first, that if we choose to consider the nitric acid as composed of nitrogen and oxygen, the acid contained in the neutral nitrate cannot possibly contain oxygen in any quantity which is an in. tegral multiple of the oxygen in the base; and secondly, that in the subnitrate here described, the base can be no integral multiple of that quantity of the same base with which the same quantity of acid is combined in the neutral nitrate. Consequently the want of agreement between the results cannot depend on errors in the analyses, but the last described subsalt is either a double combination with the base, or there are some causes for which the nitric acid, when united with the greatest possible quantity of the base, retains the oxygen in the nitrogen so strongly, that it has 
no longer the properties of oxygen, and can therefore no longer be taken into the account. The following example confirms the probability of this last view of the subject; hut the complete explanation of this phrnomenon would probably lead us a great step further in the doctrinc of chemical proportions.

\section{Sulnitrate of the Oxide of Copper.}

I have prepared this salt in three different ways: (A) by gently heating the dry neutral salt, and washing away the undecomposed portion with boiling water; (B) by precipitation of the neutral nitrate with lime water $;$ and $(C)$ by precipitation with caustic ammonia, which leaves part of the copper in the solution. All these three methods afforded precisely the same salt.

I obtained from this salt by ignition, in several experiments, $65 \cdot 6$ to 66 per cent. of black oxide of copper, and the acid disengaged was in great measure liquid. Consequently this salt contains water of crystallization, and according to the computation hereafter to be detailed, it must be thus constituted:

$$
\begin{aligned}
& \text { Nitric acid } \quad . . \quad \ldots 18.9 \\
& \text { Oxide of copper } \quad \ldots \quad \ldots 66.0 \\
& \text { Water } \quad . \quad \text {.. } 15.1
\end{aligned}
$$

The 66 parts of oxide of copper contain 13.2 of oxygen, which answer to 18.9 parts of nitric acid, if considered as composed of nitrogen and oxygen. The remaining $15 \cdot 1$ parts must have been water, and have contained 13.32 parts of oxygen. If we wished to compute this result according to another view of the composition of the nitric acid, we should obtain no relation between the oxygen of the base and that of the water, that can be expressed by an integral proportion; for 13.2 parts of oxygen would, according to this view of the subject, be contained in only 15.04 parts of nitre acid, and consequently the oxygen of the water would exceed in quantity that of the base, and yet not amount to twice as much. But if we woudd assume that the oxygen of the acid vere twice as much as that of the base, the salt would contain 300 s parts of nitric acid, and 3.42 of water, and the oxygen of the water would again abserve no integral proportion to that of the base. And if we consider the salt as a double combination of subnitrate of the oxide of copper with hrdrate of the same oxide, we still obtain no satisfactory explanatıon.

The analysis of this sait appears therefore to confirm the idea before mentioned, that in the salts in which the nitric 
acid is saturated with the greatest possible quantity of a base, the acid contains an equal quantity of oxygen with the base, so far as we consider it as composed of oxygen and nitrogen, and do not take into account the oxygen of the nitrogen. We shall obtain another confirmation of this statement from the subsubnitrite of the protoxide of lead, to which we shall now proceed.

\section{The Nitrites.}

Since the proofs which, as we have seen, may be derived from the analysis of the neutral nitrates in favour of the composition of ammonia and nitrogen, are so highly important and indispensable, and since the ideas, to which they lead, are contrary to the older opinions, and will meet with much opposition among chemists, I have considered it as essentially necessary to examine more accurately every thing which might appear ambiguous or uncertain in these proofs. In order to place beyond all doubt the truth of the opinion that the nitric acid is composed of ammonizm and oxygen, I resolved to employ an observation which I had had occasion to make in the course of my extensive investigations respecting the salts of lead.

\section{Subnitrite of the Protoxide of Lead.}

It is a fact first discovered by Proust, and since universally nnderstood, that if we boil metallic lead with a solution of nitrate of the protoxide of lead, the lead is dissolved, and we obtain a yellow fluid, which shoots into scaly yellow crystals. Mr. Proust considered this combination as a salt in which the lead was reduced to a lower degree of oxidation. Dr. Thomson on the other hand calls the same salt, which he obtained from the nitrate by means of heat, common subnitrate of the protoxide of lead. Neither of these chemists had directed lis attention to the alteration of the condition of the acid: hence arises the contradiction in their results, neither of which is more correct than the other.

I had very often found, that when I dissolved lead in nitric acid, the solution was at last of a lemon colour, without obtaining from it the scaly salt described by $\mathrm{Mr}$. Proust. Since these yellow solutions were less disposed to crystallize than the common ones, and afforded a yellow salt, I attempted to force them to crystallize by the addition of nitric acid : for it is known that several salts are precipitated from their solutions in water by the addition of uncombined acid; probably because the capacity of the 
water is diminished by this adhion. The colour diss?peared immediately, and nitrate of the plotoxisle of lead was crysiallized in abundance. But these solutions mixed with nitric acid had always so suffocating a smell of nitrous gas, withsut bowever exhbiting red vapours, that I was obliged to remore them out of the laboratory. I now poured nitric acid on a portion of the rellow salt, and gently heated the mixture: in the mean time small bubbles of gas were disengaged, which, even at the bottom of the vessel, before they came in contact with the air, appeared of a red colour. The aceic acid produced the same apparance. It was therefore beyond ail doubt that this yellow salt contained a combination in nitrous acil with the protoxide of lead, from which it probably derived the yellow colour.

1 immediately determined to examine how the oxygen of the nitrous acid was related to that of the base, and if this relation would not afford a new proof my idea of the composition of nitrogen. For this purpose I boiled in a sinall glass flask a solution of 20 grammes of nitrate of the protoxide of lead with $12.4 \mathrm{gr}$. of thin hammered lead; that is, with precisely as much as the salt already contained. After some hours, the lead was completely dissolved, and the solution had assumed a full yeliow colour. While it was cooling, it congealed completely into a scaly yellow mass, which allowed a coluurless fluid to be pressed out of it. The solution had a taste rather astringent than sweet, and acted on reddened litmus paper precisely as an alkali. This was also the case with the crystals. Acids evolved nitrous acid in great quantity from this salt. It is therefore a subnitric of the protoxide of lear. Hence it appears that there must be a distinct neutral combination of the nitrous acid with the protoxide: of this I shall speak hereafter, and first endeavour to ascertain the composition of this subsalt.

The crystals that had been obtained were levigated, well dried, then heated in a small glass retort, and at last strongly ignited, until no more nitrous gas was disengaged. The salt dud not meit in the heat. It emitted partly gaserus, partly fluid, red, smoking nitrous acid, and consequently contained crme water of crytallization. The part of the oxide of lead, which had not been frrsed, was of a fine light yellow, and weighed, in different experiments, $79.5,79 \cdot 75$, to 80 per cent. of the salt which had been employed.

If we consider the nitrous acid as composed of nitrogen and oxygen, it contains for 63.1 parts of oxygen 39.5 of nitrogen. If, on the contrary, we regard it as composed If 3 
of ammonium and oxygen, it consists of 15.88 parts of ammonium with $84 \cdot 12$ of oxvgen in 100 . In the quantity of protoxide of lead, which we have obtained in these experiments, there are from 5.70 to 5.72 parts of oxygen, which must be an aliquot part of the oxygen contained in the 20 per cent. of acid expelled. If we consider nitrogen as the radical of the nitrous acid, this acid cannot contain three times as much oxygen as the base. The quantity of nitrous acid which contains twice 5.72 parts of oxygen is 18.13 ; and 1.87 parts only would remain for the water, which is manifestly too little, since in the distillation of this salt the greatest part of the acid is obtained in a liquid form.

In order to ascertain this point, I dried a quantity of the subsalt very perfectly, until the acid began to escape, so that all water adhering to it mechanically must have been expelled: the salt had assumed a darker colour, and, when ignited in a retort, gave, as before, liquid acid, leaving $81 \cdot 3$ per cent. of protoxide. Since now the 18.7 per cent. thus expelled was chiefly liquid, as before, it is utterly impossible, that the nitrous acid should contain twice as much oxygen as the base of the salt; for in this case nothing would be left for the water. If again it only contained an equal quantity of oxygen with the base, the salt would contain only 10.93 parts of water of crystallization, and the oxygen of this water would observe no regular proportion to that of the base. Consequently the composition of this salt will not in any manner agree with the laws which prevail with respect to the other salts, so far as we take nitrogen for the radical of the nitrous acid.

If on the other hand we considered the nitrous acid as composed of ammonium and oxygen, and assumed that there is twice as much oxygen in the acid as in the base that neutralises it, the quantity of the nitrous acid in this salt would amount to 13.57 or 13.6 per cent., and 6.4 to 6.68 would remain for the water of crystallization. This water would contain 5.64 to 5.88 of oxygen; and we may safely conclude, that the base and the water of crystallization contain equal quantities of oxygen, and the acid twice as much, not reckoning that which belongs to the nitrogen. Hence the proportions of the component parts of the subnitrite of the protoxide of lead are nearly these :

Protoxide of lead.......80.0

Nitrous acid .........13.6

Water..............6.4

We will now, in order to investigate this supposition more accurately, examine the composition of the subsalt 
more minutely. We have already seen that 100 parts of nitric acid, with $205 \cdot 1$ of protoxide of lead, afford a neutral nitrate of lead. If we wish to reduce these 100 parts of nitric to nitrous acid, we must deprive them of $\frac{1}{5}$ of their whole quantity of oxygen, including that which belongs to the nitrogen. If now in all nitrates the oxygen of the acid is six times that of the base, it must amount in 100 parts of the nitric acid to $6 \times 14 \cdot 66=89$ parts. Now $\frac{8 g}{5}=17 \cdot 6$, and 100 parts of nitric acid will therefore afford $100-17 \cdot 6=$ $82 \cdot 4$ of nitrous acid, containing $70 \cdot 35$ of oxygen : [or $88-$ $17 \cdot 6=70^{\cdot 4}$.] I must here again remark, that if the quantity of the oxygen of the bases has been assumed a little too great, the error must have a considerable effect here on account of the multiplication by 6 : this however has no effect on the representation here developed. If now the lead, which is dissolved by the solution of the nitrate, on which we operate, takes up the $17 \cdot 6$ of oxygen, the solution must contain a quantity of the base of which the oxygen amounts to 32.26 , including the protoxide which was present in the first instance, containing 14:66. According to the analysis above related, the nitric acid must contain twice as much oxygen as this, that is, "64.54." But we have seen that it contains in fact 5.48 more, that is, 70.35 : [or rather 5 . 88 more, $=70 \cdot 4-2 \times 32 \cdot 26$.] If therefore this computation is correct, a part of the nitrous acid must at the same time be decomposed, and consequently nitrous gas or nitrogen must be disengaged. This evolution of gas, arising from a dissimilar decomposition of the nitric acid, is denied by Mr. Proust, and also by Mr. Gehlen. But may it not actually take place? Or rather, How could the nitrate of the protoxide of lead be constituted if it did not take place? The nitric acid would otherwise be required to saturate a quantity of protoxide of lead, of which the oxygen amounts to $\frac{1}{5}$ of that of the acid, considered as having ammonium for its radical, or to $\frac{1}{4}$, as composed of nitrogen and oxygen. This however would suppose, if my analysis of the nitrate of the protoxide of lead is at all correct, in the 100 parts of nitric acid, which saturate $205 \cdot 1$ of the protoxide, a quantity of water of which the oxygen is equal to that of the protoxide; since 100 parts of dry nitric acid would be required to saturate as much of the protoxide as contains 17.59 parts of oxygen. But my experiments on the analysis of the nitrates of the protoxide of lead and of ammonia prove incontrovertibly, as it appears to me, that no such water is concealed in the acid. Consequently the cunversion of the nitrate of the protoxide of lead into a subnitrite is not pos- 
sible without a decomposition of a part of the nitrous acid, and consequently without evolution of gas.

On this subject I was satisfed by means of the following experiment :-I put into a suall glass flask 12 "graius" of nitrate of the protoxide of learl, and $10 \mathrm{gr}$. of lead hammered thin. I filled the fins with boiled water, and introduced into its mouth a tube for the reception of gas, filled also with water. The flask was slowly heated over a spirit lamp, until the fluid came near to the boiling point. The lead began by degrees to be dissolved, and a number of very small bubbies rose from it, as from a conductor acting on water in the galvanic circuit. I did not'suffer the fluid to boil; and in this manner a quantity of gas was collected, which was not condensed in conling. Finally I male the fluid boil, and stopped the experiment, when the lead began to be covered with a yellow brown pellicle. It was found that $7 \cdot 64 \mathrm{gr}$. of lead had been dissolved, and $1.8 \mathrm{cubic}$ inch of gas had been diseniratred; the thermometer standing at $12^{3}\left[51^{1}\right]$. When the gas was mixed with oxygen gas, it was condensed into red vapours, which were wholly absorbed by water: consequently it was nitrous gas. In other experiments, in which I peiformed the solution of the lead in retorts with tubulated receivers luted to them, the oxygen gas of the receiver was absorbed, and the water that disti!led over was very perceptibly acid. Consequently the decomposition of a simall part of the nitrous acid, while the lead is dissolved in the nitrate of the protoxide, is put beyond all doubt by this experiment.

I was in hopes of being able to determine the quantity of the lead clissolved more accurately, by allowing the solution to boil upon more lead than it ought to be able to dissolve according to the computation. For this parpose I poured on 12.5 "grains" of very pure lead hammered thin, in a very long-necked flask, a solution of $10 \mathrm{gr}$. of nitrate of the prot. oxide of lead in $500 \mathrm{gr}$. of water, and boiled the mixture for 12 hours. The orifice of the flask was closed with a cork, having a glass tube fixed in it, which allowed the gas to pass through. After twelve hours, the solution was poured into a bottle, which it nearly filled, and then was loosely stopped. To my great surprise, only $.85 \mathrm{gr}$. of the lead were left undissolved. The solution, when poured off, crystallized in the form of small scales of a brick colour, and the fluid, which remained behind, had lost its colour. It was boiled down to $\frac{2}{3}$, and then, being put into a bottle, deposited two different groups of crystals. The one was the yellow subnitrite of the protoxide of lead, already described: 
scribed; the other, which was of the same nature with the first deposition, formed small brick-coloured spots, exactly like the fructifications of fern, which constituted a subsubnitrite of the protoxide.

By the formation of this subsubsalt, I found myself disappointed in my expectation of being able to determine the quantity of lead necessary for the firmation of the subsalt. 1 was therefore obliged to endeavour to determine it by approximation, boiling the nitrate of lead in distilling vessels with different quantuties of lead, and remarking the greatest quantity that could be furmed without the production of any subsubsalts. In the first cxperiment, 10 "grains" of nitrate of the protoxide of lead dissolved $7 \frac{2}{3} \mathrm{gr}$. of lead, without any traces of a subsubsalt. I then heated again the solution which had cooled, and put in $1 \mathrm{gr}$. of lead, with which I boiled it for an hour. Of this $-28 \mathrm{gr}$. were dissolved, and while the solution was cooling, some groups of subsubsalt were formed. Another portion of $10 \mathrm{gr}$. of nitrate of lead was boiled with $7.9 \mathrm{gr}$. of lead, until it was completely dissolved; while the solution was cooling, some slight traces of the substbsalt appeared. A third quantity, in which $7.8 \mathrm{gr}$. of lead had been dissolved, showed indeed no very distinct traces of a subsubsalt; but the lowest part of the crystallized mass, at the bottom of the vessel, appeared to be somewhat redder than the upper part. And since the subsubsalt is not completely insoluble in cold water, I thought I had no reason to expect a more accurate determination of the question by this mode of approximation.

It is easy to compute how much lead must be dissolved by the nitrate of the protoxide of lcad, in order llat it may be changed into the subnitrite. For if, according to the later analysis already related, the neutral subnitrite of the protoxide of lead contains in 305.87 parts 100 of the nitric acid, which, in order to become nitrous acid, nust give out $17 \cdot 6$ parts of oxygen, or, according to the determination from the volumes of the gaseous component parts of the nitric acid, $17 \cdot 39.5$; the protoxide of lead, which is formed during the process, is not aufficient to bling all the nitrous acid to the same dogree of saturation, but there is an excess of 5.74 parts of nitrous acid. It will be found by a very easy calculation, that when nitrous acid becomes nitrous gas, it loses a fourth of its whole quantity of orygen, aud consequently that two parts of nitrous acid must be decomposed in order to form the protoxide of lead, which malets the subsalt with one part of the acid [considering the acid 
in these salts as containing twice as much oxygen as the base, G.] Of the remaining $5 \cdot 74$ parts of nitrous acid, 3.826 must therefore have been decomposed, and must have afforded 805 of oxygen to the lead. These, added to the " 17.59 " parts of oxygen before mentioned, give " 18.375 ," which have been taken up by the lead dissolved; but 18.375 parts of nxygen combine with 238.8 of lead. If now 305.87 parts of nitrate of the protoxide of lead dissolve 238.8 of lead, 100 must dissolve 78; and we have seen that in these experiments the formation of the subsubsalt began exactly at this point.

Perhaps none of the indirect proofs of the true composition of the nitric acid, and at the same time of ammonia and nitrogen, is stronger than this. For the observations here adduced, even if they have no pretensions to the greatest accuracy, cannot possibly be so erroneous, as to render the formation of the subnitrite of the protoxide of lead compatible with any other idea of the composition and the capacity of saturation of these two acids.

\section{Neutral Nitrite of the Protoxide of Lead.}

I now wished also to be acquainted with the neutral nitrite, and for this purpose I adopted the following process : I mixed a saturated boiling solution of the subsalt with so much sulphuric acid as was required in order to saturate half of the protoxide contained in it: I found however that the experiment must be made in a long-necked task, for otherwise a part of the nitrous acid will escape in the form of gas. I obtained a saturated solution of a golden yellow colour, which did not crystallize when cold; and, when I attempted to concentrate it by evaporation in a sand heat, was partly decomposed, and afforded subnitrate of the protoxide. I therefore left a part of it to evaporate spontaneously; and by degrees a dark yellow salt was deposited from it, in octahedral crystals. The yellow salt thus obtained is considerably more soluble in water than the neutral nitrate. If it is dissolved in water which has been boiled, and still remains hot, it leaves a small quantity of subnitrate, which has been formed during the evaporation of the water: in water which has not been boiled, this residuum is still more considerable. Since the salt cannot be obtained dry in a state of perfect purity, we camnot expect its analysis to be completely accurate.

Ten grammes of this salt were exposed to heat in a small glass retort. It melted, and in this state resembled the muriate of the protoxide of lead or of silver; it had assumed

a dark 
a dark brown colour, and frothed very much while it was decomposed. A part of the acid which escaped was in the form of a gas; another part was collected as a liquid in the receiver: the salt contains therefore water of crystallization. A melted protoxide remained in the retort, weighing seven "grains" [grammes]. Without doubt this salt contains at least twice as much acid in proportion to the hase, as the subnitrite, and consequently the nitrous acid must saturate in the neutral salt a quantity of the protoxide containing $\frac{1}{4}$ as much oxvgen as the acid; that is, 100 parts of the acid must saturate $294^{\cdot} 1$ of the protoxide. This is the less questionable, since the 100 parts of nitrous acid, considered as composed of nitrogen and oxygen, contain three times as much oxygen as the $294 \cdot 1$ parts of protoxide; so that both views of the subject are consistent with this result. If now the water of cryctallization contains an equal quantity of oxygen with the base, the composition of the neutral nitrite of the protoxide of lead must be this :

$$
\begin{aligned}
& \text { Protoxide of lead .. ..70.375 } \\
& \text { Nitrous acid .. } \quad . . \quad \text {.. } 83.925 \\
& \text { Water .. }
\end{aligned}
$$

In the experiment, the salt lett only 70 per cent. of the protoxide: the slight difference of nearly $\frac{4}{1000}$ probably depends on the gradual oxygenization of the nitrous acid during the evaporation, whence the salt must contain a smaller quantity of the base.

\section{Sulsubnitrite of ihe Protoxide of Lead.}

The subsubnitrite of the protoxide of lead is a salt but little soluble in cold water. While the solution is cooling, it shoots into small crystalline scales of a dark brick colour. The solution is decomposed by exposure to the air, or by mixture with unboiled water, and copiously deposits a white powder. The dry salt may be kept in the air without alteration. It does not melt by heat, and at a temperature not very high it may be freed from all its water, without the extrication of any part of the acid; sn that it seems to contain no water of crystallization. When I ignited $10 \mathrm{gr}$. of the subsubsalt well dried, in a small glass retort, I obtained only gaseous nitrous acid, and $8.952 .5 \mathrm{gr}$. of protoxide were left behind: conscquently this salt is thas composed:

$$
\begin{aligned}
& \text { Protoxide of lead } \quad . \quad \text {.. } 3 \% 825 \\
& \text { Nitrous acid } \quad . \quad \ldots \quad \ldots 10 \cdot 175
\end{aligned}
$$

We find on computation, that this quantity of nitrous acid, considered as composed of nitrogen and oxygen, contains the same quantity of oxygen with the protoxide, agreeing 
agreeing almost to the last places of decimals: and that the agreement no longer remains, if we take into account the oxygen of the nitrogen. In two other experiments 1 ohtained $89^{\circ} 5$ and $89^{6} 6$ per cent. of the protoxicte trom this salt.

We have here a new confirmation of the idea already suggested, that in the suhnitrates, in which the acid and the protoxide of lead contain equal quantities of oxygen, the nitrogen must be considered in the computation as a simple substance. But when, on the other band, the mitrous acid contains a quantity of oxygen which is a multiple of that which is contained in the base, the composition of the salt agrees only with the general law on the supposition that oxygen is contained in the nitrogen. Respecting the cause of this singular circumstance I will not hazard a conjecture.

If we calculate the quantity of a base with which 100 parts of nitrous acid are combined in the three salts here described, we find that in the subsalt they take up twice as much, and in the subsubsalt three times as much, of the protoxide, as in the neutral salt. But in the three combinations of the nitric acid such a regular progression is not observable, for the quantities of the base combined with 100 parts of the acid are represented by 1, 2, and 4.75. This irregularily can only depend on the compound nature of nitrogen, and appears therefore to be an additional proof of that nature.

It is easy o sec, that the formation of the subsalt takes place at the expense of the nitrous acid. 1 found by an experiment, that nitrous gas was disengaged in the process, and in this gas I could find no perceptible trace of nitrogen. According to the furegring calculations, the nitrate of the protoxide of lead, in being converted into subsubnitrite, dissolves a weight of lead nearly equal to its own. In one of the experiments here related, 100 parts of nitrate of lead bad dissulved 1 i $6 \frac{1}{2}$ of ledd; but the experiment was performed in a long-necked thak, in which a considerable portinn of nitrous gas was united with the oxygen of the air that forced its way in, and returned into the flask in the form of nitric acid. This happens more particularly when the subsalt has been formed, since then three parts of the nitrous acid nust be decomposed and converted into nitrous gas, in order to change one part of the salt into a subsubsalt. This does not happen in an apparatus for distillation, becanse in this case the newly fornted acid collects in the receiver; in which the water that is condeused is more or less acid, for reasons that may easily be imagined, accordingly 
ingly as the heat has kept up the boiling of the fluid more or less equabiy.

If we buil a weakly acid solution of nitrate of the protoxide of lcad in an open vessel, with more lead, we obtain a yellow solution, which deposits yellow crystals. I thought at first that this might be a double salt, containing two acids, and therefore attempted to analyse it with accuracy; but I found that it did not remain always alike, that even the same specimen was more or less yellow in different parts, and that the portion last deposited contained the nitrite in greater quantity than the rest. This salt was therefore only a contemiporary crystallization af the two separate salts mixed together. By powdering it, and exposing it to the air, it loses gradually its yellow colour, and when dissolved in water it leaves some subnitrate behind. If it were really a double salt, in which the acids were combined each with hall of the base, it ought to leave, after ignition, 68.9 per cent. of the protoxide. But I obtained only from 67.5 to 68.5 per cent., accordingly as I texanined the earlier or the later crystallizations.

I must also mention another phænomenon of the neutral nitrite of lead, which it probally exhibits in common with. the other nitrites. If We concentrate a solution of this salt by exposure to heat, the acid becomes more oxygenized; and since the newly-formed nitric acid then finds in the salt $\frac{1}{4}$ more of the base than it can saturate, $\frac{2}{3}$ of the newlyformed salt separate as a subnitrate', while $\frac{3}{3}$ remain in the solution as a nentral nitrate. When the Jiquid has acquired a certain degree of concentration, at a temperature approaching to the boiling point, an effervescence takes place, nitrous gas is discharged, and subnitrate and subsubuitrate are formed.

The neutral nitrite mav therefore be decomposed in two ways. Eilher the acid is more oxygenized, at the expense of the air, and a mixture of $\frac{2}{3}$ of subnitrate and $\frac{3}{5}$ of nitrate is formed ; or half of the ammonium of the acid is clisengaged by the heat, with as much oxygen as is necessary for the formation of nitrous gas, and the remaining oxygen changes the other half of the ammonium into nitric acid, so that $T^{4_{0}}$ of the weight of the nitrous acid escape as nitrous gas, while $\frac{6}{10}$ are retained as nitric acid, and form a mixture of $\frac{7}{8}$ of subnitrate and $\frac{1}{8}$ of the subsubnitrate of the protoxide of lead. The fluid remains, as long as it is boiling, tolerably clear; hut when it cools, the subsalts are deposited. The same happens also when the solution is diluted with water. The transformation of the nitrous into nitric acid, by a dif- 
ferent distribution of the oxygen among different portions of the radical, is common to this with the other imperfect acids.

\section{Other Nitrous Salts.}

I have attempted to prepare other nitrous salts by means of the nitrite of the protoxide of lead, mixing it with various sulphates; but I have hitherto ubtained little more than a conviction of the possibility of their being exhibited. When, for example, I mixed the sulphate of the oxide of copper with this nitriti, I obtained a grass green solution, which when exposed turthe air deposited by degrees subnitrate of the oxide of copper, and finally, after several weeks, became again blue. The same happened still more rapidly when heat was applied. I attempted to prepare this salt from the nitrate of the oxide of copper, by digesting it on copper ; but I could not succeed in obtaining a nitrous salt, probably because the nitrous acid forms no such subsalt with the oxide of copper as with the protoxide of lead.

Nitrite of ammonia, prepared in the same manner as the nitrite of the oxide of copper, is a colourless salt, which is decomposed at a temperature not very high. Between $40^{\circ}$ and $50^{\circ}\left[104^{\circ}\right.$ and $\left.122^{\circ}\right]$ the solution continually emits bubbles of pure nitrogen; when heated to the boiling point, it froths very considerably, and the extrication of gas is more rapid; and as long as the solution is not too much concentrated, nothing but nitrogen gas is produced, and the salt remains in a neutral state. I attempted to obtain it in a dry form, leaving the solution exposed in shallow dishes to a current of dry air ; and 1 obtained a saline mass indistinctly crystallized, which resembled the nitrate of ammonia. When melted in a small retort, it afforded much gas, and a quantity of water strongly impregnated with ammonia. The gas obtained was not reddened by oxygen, and had all the properties of the nitrons oxide.

These appearances are easy to be explained. The nitrous acid neutralises a quantity of the base, which contains $\frac{1}{4}$ as much oxygen as the acid. The oxygen of the acid, exclusive of that of the nitrogen, is then exactly sufficient to change into water all the hydrogen which is produced during the further oxidation of the ammonia, while the nitrogen of the acid and that of the ammonia are disengaged together in the form of gas. The nitrite of ammonia is therefore decomposed, when its solution is not too much concentrated, into water and nitrogen, and perhaps this salt affords the cheapest and most certain mode of obtaining ni- 
trogen gas in a state of perfect purity. The acid and the alkali afford equal quantities of nitrogen, but the alkali contains half as much more ammonium as the acid. When the dry salt is heated, and then produces, as we bave seen, very different substances, the process may be thus explained: the nitrite of ammonia is decomposed on one hand, like the nitrite of the protoxide of lead, into nitrous gas, nitrate of ammonia, and uncombined ammonia, since this alkali affords no subsalt; and on the other hand another part of the alkali is resolved into water and nitrogen; and since the nitrous gas and the nitrogen are in contact at the instant of their formation, they unite, and conscitute nitrous oxide; so that the products of this twofold decomposition are nitrous oxide, water, uncombined ammonia, and nitrate of ammonia, which, being further decomposed, augments the quantity of the nitrous oxide and of the water.

$I$ believe that these experiments are sufficient in the first place to illustrate more fully the doctrine of the composition of the nitric acid; and secondly, to show that the nitrous acid is a distinct acid, producing peculiar salts with different bases, and neutralising such a quantity of them as contains $\frac{1}{4}$ as much oxygen as itself. Some modern chemists had been disposed to consider this acid as a compound of nitric acid with nitrons gas, which was destroyed by the combination of the acid with a base. This opinion was however founded on experiments which by no means justified the inference drawn from them.

The knowledge of the nitrites is indispensable to the explanation of some appearances which the nitric acid exhibits. It is well known, for example, that diluted nitric acid, formed from concentrated colourless acid, is a much less powerful solvent of many metals than that which is made from the smoking acid. If the smoking nitric acid were nothing more than a solution of nitrous gas in nitric acid, it would be inconceivable, how the nitrons gas could be so efficacious, as it cannot be decomposed by the bodies to be dissolved. Since however we know that the nitrous acid is a peculiar acid, which is more easily decomposed than the nitric, there is no longer any thing paradoxical in the superior efficacy of the solvent made by diluting the smoking acid.

[End of the Szcond Continuation.] 